\title{
BMJ Open Role of gender, family, lifestyle and psychological factors in self-rated health among urban adolescents in Peru: a school-based cross-sectional survey
}

\author{
Bimala Sharma, ${ }^{1,2,3}$ Eun Woo Nam, ${ }^{1,2,3}$ Dohyeong Kim, ${ }^{1,2,3}$ Young Min Yoon, ${ }^{1,3}$ \\ Yeunju Kim, ${ }^{3}$ Ha Yun Kim ${ }^{1,3}$
}

To cite: Sharma B, Nam EW, Kim D, et al. Role of gender, family, lifestyle and psychological factors in selfrated health among urban adolescents in Peru: a school-based crosssectional survey. BMJ Open 2016:6:e010149.

doi:10.1136/bmjopen-2015010149

- Prepublication history for this paper is available online. To view these files please visit the journal online (http://dx.doi.org/10.1136/ bmjopen-2015-010149).

Received 1 October 2015 Revised 10 January 2016 Accepted 11 January 2016

CrossMark

\footnotetext{
${ }^{1}$ Yonsei Global Health Center, Yonsei University, Wonju City, Gangwon-do, the Republic of Korea ${ }^{2}$ Institute for Poverty Alleviation and International Development, Yonsei University, Wonju City, Gangwon-do, the Republic of Korea

${ }^{3}$ Department of Health Administration, Graduate School, Yonsei University, Wonju City, Gangwon-do, the Republic of Korea
}

Correspondence to Professor Eun Woo Nam; koreahealth@hotmail.com

\section{ABSTRACT}

Objective: We examined the role of gender, family, lifestyle and psychological factors in self-rated health. Design: Cross-sectional study.

Setting: A total of 970 randomly selected students from 11 secondary schools in Lima and Callao, Peru, participated in 2014.

Main outcome measure: Self-rated health was measured with a single item: 'In general, how would you rate your health?' Responses were arranged along a five-point Likert-type scale: 'excellent', 'very good', 'good', 'fair' and 'poor'. The outcome variable was dichotomised as 'good' (excellent, very good or good) or 'poor/fair' (poor or fair).

Methods: We calculated adjusted ORs (AORs) and $95 \% \mathrm{Cls}$ for poor/fair self-rated health using multivariate logistic regression analyses at 3-graded levels.

Results: $32.5 \%$ of the respondents had fair/poor selfrated health, $23.7 \%$ of the total males and $40.0 \%$ of the total female samples. Males were less likely to have poor/fair self-rated health (AOR $0.61 ; \mathrm{Cl} 0.41$ to 0.91 ). Poor family support strongly increased the likelihood of having poor/fair self-rated health (no support, (AOR 3.15 ; $\mathrm{Cl} 1.63$ to 6.09 ); low support, (AOR 2.50; $\mathrm{Cl}$ 1.29 to 4.85$)$ ). The other associated variables were missed meals due to a shortage of food (AOR 1.97; Cl 1.15 to 3.36 ), television watching during leisure time (AOR 1.70; Cl 1.09 to 2.67), low physical activity (AOR 1.49; Cl 1.03 to 2.15), school absenteeism (AOR 1.54; $\mathrm{Cl} 1.03$ to 2.31) and perceived life satisfaction (AOR 0.28 ; $\mathrm{Cl} 0.15$ to 0.25 ).

Conclusions: Gender, missing meals due to a shortage of food, family support, physical activity and life satisfaction influenced self-rated health among adolescents in Peru. Interventions that focus on promoting physical activity for at least $1 \mathrm{~h}$ each day for 3 or more days per week, food security and strengthening supportive family roles may improve self-rated health during adolescence.

\section{INTRODUCTION}

Self-rated health (SRH) is a simple and reliable measure of general health. ${ }^{1}{ }^{2}$ SRH

\section{Strengths and limitations of this study}

- The study measured self-rated health of adolescents attending school using a five-item Likert-type scale on subjective health. Cross-sectional associations between gender, family support, lifestyle and psychological factors with self-rated health were examined.

- A structured questionnaire developed from the Global School-based Student Health Survey was administered.

- Participants were selected using a proportionate simple random sampling technique from 11 randomly selected schools; participation was completely voluntary.

- Measurements for health, lifestyle-related and other variables were based on self-reported information; there is the possibility of a methodological bias.

- Owing to the cross-sectional nature of data, it is difficult to establish cause-and-effect relationships between self-rated health and our explanatory variables.

predicts morbidity patterns, future health status, health service utilisation and quality of life. ${ }^{2-4}$ It is also an important independent predictor of mortality. ${ }^{5-8}$ Most studies assessing SRH have focused on either elderly or adult samples, as these were the original samples whereby research first established $\mathrm{SRH}$ as an appropriate measure for general health status and future mortality patterns. ${ }^{7-}$ ${ }^{11}$ SRH measurement during adolescence is essential in order to support public health efforts for advocating adolescent health. SRH assessment among adolescents is also a good measure of enduring self-concepts of health $^{12}{ }^{13}$ and is strongly associated with general well-being and psychosomatic symptoms. ${ }^{14}{ }^{15} \mathrm{SRH}$ is moderately stable over time and deteriorates along with poor general wellbeing and health risk behaviour during 
adolescence. $^{13} 16$ Previous studies have shown a prevalence of poor SRH ranging from $10 \%$ to $30 \%$ across various study settings and samples. ${ }^{14} 17-20$

Adolescent health is strongly affected by social factors, including income inequality, family support, school environment and peer influence. ${ }^{21} 22$ Additionally, adolescence is the period during which health-related behaviours, such as smoking, alcohol consumption, drug use, nutrition-related behaviours and physical activities, are formed. These behaviours have long-term health and social consequences. Since health status and health-related behaviours during adolescence are strongly associated with these variables in adulthood, certain social determinants of adolescent health are similar to those for the general population. ${ }^{21}$ In general, adolescents tend to be healthy; however, a large number of adolescents report subjective symptoms and health problems, ${ }^{1923}$ and the use of medications for simple ailments is common. ${ }^{24} \mathrm{~A}$ high percentage of young people have psychosomatic symptoms and consider themselves to be stressed. ${ }^{23}$

Peru is the third largest country in South America, with a total area of $1285216 \mathrm{~km}^{2} .^{25}$ According to the latest National Census conducted in 2007, Peru had a total population of $27412157 ; 20.7 \%$ of the population was aged 10-19 years, which represented the largest percentage of the adolescent population in the country. ${ }^{26}$ About $76 \%$ of the population lives in urban areas; $30.8 \%$ live in Lima, the largest city in Peru. ${ }^{26}$ With a gross national per capita income (purchasing power parity, PPP) at $\$ 11360$, Peru lies within the 'upper-middle-income' countries according to World Bank classifications. ${ }^{27}$ Major public health issues for adolescents in Peru include substance abuse, physical assault and injuries, a sedentary lifestyle and unhealthy food habits. ${ }^{28}$

Adolescents' rating of their own health is shaped by their perceptions of physical, social and psychological health dimensions. ${ }^{12}{ }^{14}$ Various studies have shown that $\mathrm{SRH}$ in adolescents is significantly influenced by physical health, as well as by a large number of personal, socioenvironmental, behavioural and psychological factors. $^{12} 141517$ Thus, having an understanding of adolescent health status, and how it is affected by psychological, behavioural and socioenvironmental factors, is the starting point for improving adolescent health. In most studies, SRH is measured with a single question asking respondents to rate their overall health on a fivepoint scale from 'excellent' to 'poor'. SRH is being increasingly used as a valid health status measurement tool in several countries, including the USA. ${ }^{13} 2930$ While it is important to identify SRH status and determinants among adolescents, there have been few studies on adolescent SRH in Peru. Therefore, the objective of the present study was to determine the role of gender, family factors, lifestyle and psychological factors on SRH among adolescent samples in Lima and Callao, Peru. On the basis of previous studies, we predicted that gender, family support, behavioural and psychological factors would contribute to health perceptions within our adolescent participants.

\section{METHODS}

\section{Study setting, design and sampling}

Information for this study was collected as part of a health survey among secondary school students. The field study was conducted from 15 September to 31 October 2014, in collaboration with the Korea International Cooperation Agency (KOICA), Peru office. This was a cross-sectional study conducted in one district of Lima (Comas) and two districts of Callao (Bellavista and Ventanilla), which were purposively selected. Three areas from Comas (Santa Luzmila II, Laura Rodriguez Dulanto and Carlos Philips), one area from Bellavista (Bellavista) and two areas from Ventanilla (Pachacutec and Mi Peru) were included in the survey. Of the 17 secondary schools from the study areas, 11 were randomly selected. The target population was secondary school students. Five secondary level grades were considered as strata. One stratum from each school was selected via simple random sampling; students from each stratum were selected using a proportionate simple random sampling technique based on the number of students in each stratum. The total calculated sample size was 975 using the following formula, $m=\left[\mathrm{Z}^{2} \times \mathrm{V} \times \mathrm{M}\right] /\left[\mathrm{d}^{2}(\mathrm{M}-1)\right.$ $\left.+\mathrm{Z}^{2} \times \mathrm{V}\right] \times($ def $) \times($ tnr $)$. In the formula, $m=$ the estimated student sample; $Z=$ the normal distribution value $(Z=1.96$ for a standard normal distribution at $95 \%$ confidence level); $\mathrm{P}=$ prevalence of smoking and drinking among students in Peru $\left(\mathrm{P}=0.23:^{31}\right.$ a study conducted in Peru showed that $23 \%$ of students had tried smoking or drinking, or both, within 1 year preceding the survey); $\mathrm{V}=\mathrm{P} \times \mathrm{Q}, \mathrm{Q}=1-\mathrm{P}=0.77 ; \mathrm{M}=$ total number of students in the study area $(\mathrm{M}=14787)$; $\mathrm{d}=$ margin of error $(\mathrm{d}=0.0307)$; $\mathrm{def}=$ clustering effect for the distribution of estimates (def=1.2); and tnr=adjustment factor due to nonresponses (tnr=1.18). A total of 981 students were randomly selected and invited to participate in the study; all of them were eligible participants. However, some students were absent on the day of data collection, and a few samples were excluded from the analysis because of incomplete information. Thus, 970 samples were selected for analysis.

\section{Data collection and measurement}

A self-administered structured questionnaire was developed on the basis of the Global School-based Student Health Survey in Peru (2010) and the WHO Global School-based Student Health Survey Questionnaire Modules (2013). ${ }^{28} 32$ The Global School-based Student Health Survey in Peru was adopted from the WHO survey, with a few modifications for Peruvian relevance and to align with guidelines from Peru's Ministry of Health. The questionnaire was also translated into Spanish. While most of the questions for our survey were 
adopted from the aforementioned sources, additional questions were added in collaboration with the KOICA Peru office and Ministry of Health, Peru. Trained enumerators administered questionnaires to the randomly selected students in their classrooms during regular school hours. Before completing the questionnaire, a brief orientation was provided regarding the study objectives, how to complete the questionnaire, and students were encouraged to read the instructions carefully. Students were informed that the survey was anonymous. Teachers and school staff were not allowed in the classroom during data collection.

\section{Dependent variable: SRH}

The dependent variable was SRH, as defined by the question: 'In general, how would you rate your health?'. Responses were measured on a five-point Likert-type scale as 'excellent', 'very good', 'good', 'fair' and 'poor', as has been done in other studies. ${ }^{13} 2930$ Responses were dichotomised as 'good' (excellent, very good or good) versus 'poor/fair' health (fair or poor).

\section{Independent variables}

Student age was categorised into two groups, 11-14 and 15-19 years, to examine differences between early and late adolescence. To assess economic status, we asked, 'During the last month, have you missed a meal because there was nothing to eat at home?'. The options: 'never' or 'rarely' were categorised as 'no'; 'sometimes', 'often' or 'always' was categorised into 'yes'. The question, 'During the last week, have you eaten any fruit?' was asked to assess fruit consumption behaviour. Other independent variables (family support, lifestyle and psychological variables) were measured as described below.

\section{Family support}

Family support was measured using four domains: parents' or guardians' understanding of adolescents' problems, time spent with parents or guardians, homework checked by parents or guardians, and love/affection expressions by parents or guardians. To assess parental understanding, we asked, 'During the past 30 days, how often did your parents or guardian try to understand your problems or worries?'. The responses 'most of the time' and 'always' were categorised into 'yes' and 'sometimes', 'rarely', and 'never' into 'no'. To assess time spent with parents or guardians, the following question was asked: 'During the past 30 days, how often did you spend time with your parents or guardian?'. The questions measuring homework checking and love expressions were: 'During the past 30 days, how often did your parents or guardian check to see if your homework was done?' and 'During the past 30 days, how often did your parents express love/affection toward you?'. The response options were identical to the first question, and the responses were categorised in the same way. The category 'yes' was labelled as ' 1 ' and 'no' as ' 0 ' for these four variables. The responses were combined into one variable as the measure for family support. Family support was ' 4 ' if all responses were 'yes' and ' 0 ' if all responses were 'no', with a score of 4 indicating the highest level of family support and 0 indicating the lowest level of family support.

\section{Lifestyle}

Smoking, alcohol consumption, leisure time utilisation, school absenteeism, physical activity, sexual intercourse initiation, and tooth brushing were assessed for lifestyle measurements. To measure current smoking, the following question was asked among those who had ever smoked: 'During the past 12 months, have you smoked?'. If the reply was yes, they were categorised as current smokers; if it was no, they were categorised as former smokers. Alcohol consumption was also measured in the same way. For school absenteeism, the following question was asked: 'During the past 30 days, how many days did you miss school without informing the school?'. Physical activity was measured using the following item: 'During the last 7 days, on how many days did you work out for at least $1 \mathrm{~h}$ per day?'. Responses of 'less than 3 days' were categorised into inactive and ' 3 or more into' active.

\section{Psychological factors}

To assess perceived body weight, we asked, 'How do you feel about your body weight?'. The options 'very underweight', 'underweight' or 'slightly underweight' were categorised into 'underweight', and 'slightly overweight', 'overweight' or 'very overweight' were categorised into 'overweight'. 'How do you feel about your life?' was asked to assess life satisfaction. Responses of 'very happy', 'happy' or 'a bit happy' were categorised as 'satisfied', and 'a bit sad', 'sad' or 'very sad' were categorised as 'unsatisfied'.

\section{Data analysis}

The sample data were entered and analysed using SPSS for Windows, V.21 (IBM Corp, Armonk, New York, USA). The $\chi^{2}$ tests were applied to assess any associations between our independent variables and SRH at a $5 \%$ level of significance. All significant variables in the bivariate analysis were then entered into a logistic regression analysis. Three-graded models were prepared to examine the effects of the independent variables on SRH. Model 1 included demographic and family factors, model 2 included model 1 and lifestyle factors, and model 3 comprised model 2 and psychological factors. Adjusted ORs (AORs) with 95\% CIs were computed to determine the effect sizes of the independent variables. Since it was a self-administered questionnaire survey, several variables had missing values; analysis was performed ignoring the missing data. A Hosmer-Lemeshow test was applied to determine each model's goodness-of-fit.

Prior consent was obtained from each school administration and parents or guardians. Informed consent was 
obtained from individual participants after they were fully informed about the study objectives and procedures.

\section{RESULTS}

Table 1 shows the distribution of the study sample by sex, age group and SRH. Of the 970 participants, $53.8 \%$ were female and $46.2 \%$ were male; $47.3 \%$ were in the early adolescent stage, and $52.7 \%$ were in late adolescence. The mean participant age was 14.5 years $(\mathrm{SD}=1.6$; range $=11-19$ years). About one-third, $32.5 \%$ (315) of the sample, had poor/fair SRH.

Table 2 shows bivariate analysis of the independent variables with SRH. SRH differed significantly with gender and age group. A significantly higher proportion of females to males ( $40.0 \%$ vs $23.7 \%$ ) reported poor/ fair SRH health. Missing meals, fruit consumption, family support, alcohol consumption, physical activity, leisure time use, school absenteeism, life satisfaction and perceived body mass index status were significantly associated with SRH. However, the number of close friends, smoking, sexual intercourse initiation and tooth brushing had no association with SRH; thus, these four variables were not included in the logistic regression analysis.

Table 3 shows logistic regression results examining the relationships between demographic factors, family factors, lifestyle, psychological factors and poor/fair SRH. Model 1 shows that being female, missing a meal, no fruit consumption and poor family support increased the likelihood of poor/fair SRH. In model 2, gender, missing a meal, family support, leisure time use, physical inactivity and school absenteeism were associated with poor/fair SRH. Fruit and alcohol consumption were no longer significant. In model 3 , all significant variables from model 2 and life satisfaction were significantly predictive of SRH. Males were less likely to report poor/fair SRH (AOR 0.61; CI 0.41 to 0.91). Students who missed

\begin{tabular}{|c|c|c|}
\hline Variables & Number & Per cent \\
\hline \multicolumn{3}{|l|}{ Sex } \\
\hline Male & 448 & 46.2 \\
\hline Female & 522 & 53.8 \\
\hline \multicolumn{3}{|c|}{ Age group (years) } \\
\hline $11-14$ & 449 & 47.3 \\
\hline 15-19 & 511 & 52.7 \\
\hline \multicolumn{3}{|l|}{ SRH } \\
\hline Excellent & 99 & 10.2 \\
\hline Very good & 179 & 18.1 \\
\hline Good & 308 & 39.2 \\
\hline Fair & 296 & 30.5 \\
\hline Poor & 19 & 2.0 \\
\hline
\end{tabular}

Table 2 Bivariate analysis of independent variables with $\mathrm{SRH}$

\begin{tabular}{|c|c|c|c|}
\hline Variable & $\begin{array}{l}\text { Good } \\
\text { SRH } \\
\text { N (\%) }\end{array}$ & $\begin{array}{l}\text { Poor/fair } \\
\text { SRH } \\
\text { N (\%) }\end{array}$ & p Value \\
\hline \multicolumn{4}{|l|}{ Demographic factors } \\
\hline \multicolumn{4}{|l|}{ Sex } \\
\hline Male & $342(76.3)$ & $106(23.7)$ & \multirow[t]{2}{*}{0.000} \\
\hline Female & $313(60.0)$ & $209(40.0)$ & \\
\hline \multicolumn{4}{|l|}{ Age group (years) } \\
\hline $11-14$ & $327(71.2)$ & $132(28.8)$ & \multirow[t]{2}{*}{0.019} \\
\hline $15-19$ & $328(64.2)$ & $183(35.8)$ & \\
\hline \multicolumn{4}{|l|}{ Family factors } \\
\hline \multicolumn{4}{|l|}{ Missing meals } \\
\hline Yes & $57(50.9)$ & $55(49.1)$ & \multirow[t]{2}{*}{0.000} \\
\hline No & $590(69.7)$ & $256(30.0)$ & \\
\hline \multicolumn{4}{|l|}{ Fruit consumption } \\
\hline Yes & $555(69.6)$ & $242(30.4)$ & \multirow[t]{2}{*}{0.002} \\
\hline No & $40(52.6)$ & $36(47.4)$ & \\
\hline \multicolumn{4}{|l|}{ Family support } \\
\hline 0 (no support) & $114(51.1)$ & $109(48.9)$ & \multirow[t]{5}{*}{0.000} \\
\hline 1 (low) & $116(60.1)$ & 77 (39.9) & \\
\hline 2 & $142(80.2)$ & $35(19.8)$ & \\
\hline 3 & $139(72.8)$ & $52(27.2)$ & \\
\hline 4 (high) & $119(86.2)$ & $19(13.8)$ & \\
\hline \multicolumn{4}{|c|}{ Number of close friends } \\
\hline None & $21(53.8)$ & 18 (46.2) & \multirow[t]{3}{*}{0.066} \\
\hline $1-3$ & $135(63.7)$ & 77 (36.3) & \\
\hline$\geq 4$ & $480(69.1)$ & 215 (30.9) & \\
\hline \multicolumn{4}{|l|}{ Lifestyle } \\
\hline \multicolumn{4}{|l|}{ Smoking } \\
\hline Current & $88(63.3)$ & $51(36.7)$ & \multirow[t]{3}{*}{0.226} \\
\hline Former & 74 (73.3) & 27 (26.7) & \\
\hline Never & 461 (67.6) & $221(32.4)$ & \\
\hline \multicolumn{4}{|l|}{ Alcohol consumption } \\
\hline Current & $185(64.9)$ & $100(35.1)$ & 0.031 \\
\hline Former & $86(60.1)$ & 57 (39.9) & \\
\hline Never & 344 (70.9) & $141(29.1)$ & \\
\hline Sexual intercourse & & & \\
\hline Initiated & $121(66.1)$ & $62(33.9)$ & 0.690 \\
\hline Never & $523(67.7)$ & 250 (32.3) & \\
\hline Leisure time use & & & \\
\hline Internet & $90(62.9)$ & $53(37.1)$ & 0.000 \\
\hline Television & 275 (63.8) & $156(36.2)$ & \\
\hline Outdoor activities & $228(77.0)$ & $68(23.0)$ & \\
\hline Physical activity & & & \\
\hline Inactive & $260(59.1)$ & $180(40.9)$ & 0.000 \\
\hline Active & 376 (74.9) & $128(25.1)$ & \\
\hline Everyday tooth brus & & & \\
\hline Yes & $635(68.0)$ & $299(32.0)$ & 0.89 \\
\hline No & 19 (54.3) & $16(45.7)$ & \\
\hline School absenteeism & & & \\
\hline Yes & $143(60.3)$ & $94(39.7)$ & 0.004 \\
\hline No & 504 (70.4) & 212 (29.6) & \\
\hline Psychological factol & & & \\
\hline Life satisfaction & & & \\
\hline Satisfied & $624(71.1)$ & $254(28.9)$ & 0.000 \\
\hline Unsatisfied & 27 (31.0) & $60(69.0)$ & \\
\hline Body shape satisfac & & & \\
\hline Underweight & $134(63.8)$ & 76 (36.2) & 0.000 \\
\hline Overweight & 129 (57.8) & 94 (42.2) & \\
\hline Normal & 390 (73.2) & $143(26.8)$ & \\
\hline
\end{tabular}


Table 3 Logistic regression analysis assessing the relationships between demographic factors, family factors, lifestyle and psychological factors, and poor/fair SRH

\begin{tabular}{|c|c|c|c|}
\hline Variables & $\begin{array}{l}\text { Model } 1 \\
\text { AOR (95\% Cl) }\end{array}$ & $\begin{array}{l}\text { Model } 2 \\
\text { AOR (95\% Cl) }\end{array}$ & $\begin{array}{l}\text { Model } 3 \\
\text { AOR (95\% Cl) }\end{array}$ \\
\hline \multicolumn{4}{|c|}{ Demographic factors } \\
\hline \multicolumn{4}{|c|}{ Gender } \\
\hline Male & $0.47(0.34 \text { to } 0.65)^{a}$ & $0.55(0.37 \text { to } 0.81)^{b}$ & $0.61(0.41 \text { to } 0.91)^{b}$ \\
\hline Female & 1 & 1 & 1 \\
\hline \multicolumn{4}{|l|}{ Age groups (years) } \\
\hline $11-14$ & $0.78(0.56$ to 1.07$)$ & $0.83(0.57$ to 1.19$)$ & 0.88 (0.60 to 1.28$)$ \\
\hline $15-19$ & 1 & 1 & 1 \\
\hline \multicolumn{4}{|l|}{ Family factors } \\
\hline \multicolumn{4}{|l|}{ Missing meals } \\
\hline Yes & $2.18(1.38 \text { to } 3.44)^{b}$ & $2.13(1.27 \text { to } 3.58)^{c}$ & $1.97(1.15 \text { to } 3.36)^{\mathrm{c}}$ \\
\hline No & 1 & 1 & 1 \\
\hline \multicolumn{4}{|l|}{ Fruit consumption } \\
\hline Yes & $0.57(0.34 \text { to } 0.96)^{c}$ & $0.62(0.36$ to 1.09$)$ & 0.69 (0.39 to 1.23$)$ \\
\hline No & 1 & 1 & 1 \\
\hline \multicolumn{4}{|l|}{ Family support } \\
\hline 0 (no support) & $4.75(2.64 \text { to } 8.56)^{a}$ & $3.98(2.08 \text { to } 7.60)^{a}$ & $3.15(1.63 \text { to } 6.09)^{a}$ \\
\hline 1 (low) & $3.61(1.98 \text { to } 6.59)^{a}$ & $2.97(1.55 \text { to } 5.70)^{b}$ & $2.50(1.29 \text { to } 4.85)^{\mathrm{b}}$ \\
\hline 2 & $1.44(0.76$ to 2.75$)$ & 1.41 (0.70 to 2.82$)$ & 1.27 (0.63 to 2.57$)$ \\
\hline 3 & $1.96(1.05 \text { to } 3.64)^{c}$ & $1.92(0.98$ to 3.75$)$ & $1.84(0.93$ to 3.60$)$ \\
\hline 4 (high) & 1 & 1 & 1 \\
\hline \multicolumn{4}{|c|}{ Lifestyle } \\
\hline \multicolumn{4}{|c|}{ Alcohol consumption } \\
\hline Current & & $1.18(0.78$ to 1.76$)$ & $1.12(0.74$ to 1.70$)$ \\
\hline Former & & 1.55 (0.94 to 2.57$)$ & 1.58 (0.95 to 2.64$)$ \\
\hline Never & & 1 & 1 \\
\hline \multicolumn{4}{|l|}{ Leisure time use } \\
\hline Internet & & 1.48 (0.84 to 2.59$)$ & 1.52 (0.85 to 2.70$)$ \\
\hline Television & & $1.63(1.05 \text { to } 2.51)^{c}$ & $1.70(1.09 \text { to } 2.67)^{\mathrm{b}}$ \\
\hline Outdoor activity & & 1 & 1 \\
\hline \multicolumn{4}{|l|}{ Physical activity } \\
\hline Inactive & & $1.54(1.07 \text { to } 2.20)^{\mathrm{c}}$ & $1.49(1.03 \text { to } 2.15)^{\mathrm{c}}$ \\
\hline Active & & 1 & 1 \\
\hline \multicolumn{4}{|c|}{ School absenteeism } \\
\hline Yes & & $1.47(0.99 \text { to } 2.19)^{\mathrm{c}}$ & $1.54(1.03 \text { to } 2.31)^{\mathrm{c}}$ \\
\hline No & & 1 & 1 \\
\hline \multicolumn{4}{|c|}{ Psychological factors } \\
\hline \multicolumn{4}{|c|}{ Perceived BMI } \\
\hline Underweight & & & $1.12(0.71$ to 1.77$)$ \\
\hline Overweight & & & $1.42(0.91$ to 2.21$)$ \\
\hline Normal & & & 1 \\
\hline \multicolumn{4}{|l|}{ Life satisfaction } \\
\hline Satisfied & & & $0.28(0.15 \text { to } 0.25)^{a}$ \\
\hline Unsatisfied & & & 1 \\
\hline p Value* & 0.167 & 0.369 & 0.441 \\
\hline
\end{tabular}

Source: Authors' calculation, ${ }^{a} p<0.001,{ }^{b} p<0.01,{ }^{c} p<0.05$.

*Hosmer-Lemeshow test.

AOR, adjusted OR; BMI, body mass index; $\mathrm{SRH}$, self-rated health.

meals due to a shortage of food were more likely to have poor/fair SRH (AOR 1.97; CI 1.15 to 3.36). Participants with poor family support were also at greater risk of having poor/fair SRH (no family support, (AOR 3.15; CI 1.63 to 6.09), low family support (AOR 2.50; CI 1.29 to 4.85)). Regarding lifestyle, participants who usually spent their leisure time watching television were more likely to have poor/fair SRH compared with those who usually engaged in outdoor activities during their leisure time (AOR 1.70; CI 1.09 to 2.67). Inactive adolescents who engaged in physical activity for at least $1 \mathrm{~h}$ each day for $<3$ days/week were more likely to have poor/fair SRH (AOR 1.49; CI 1.03 to 2.15). School absenteeism was associated with higher rates of poor/fair SRH (AOR 1.54; CI 1.03 to 2.31). SRH did not significantly differ between adolescents who perceived themselves as being 
overweight or underweight, as compared with those who perceived themselves as being normal weight. Adolescents who were satisfied with their lives were less likely to report poor/fair SRH (AOR 0.28; CI 0.15 to $0.25)$. Thus, on the basis of overall results from model 3 , gender, missing meals due to a shortage of food, family support, physical activity, leisure time use and life satisfaction significantly influenced adolescent SRH.

\section{DISCUSSION}

Our study revealed that a sizeable proportion of our adolescent sample $(32.5 \%)$ perceived their health to be poor/fair, and SRH was influenced by gender, family support, lifestyle and psychological factors. Consistent with the present findings, previous studies observed that $29 \%$ of adolescents reported poor SRH in Pakistan ${ }^{18}$ and $30 \%$ in Canada. ${ }^{19}$ However, studies conducted in Norway and Brazil show lower proportions of poor SRH. ${ }^{14}{ }^{17}$ In the USA, only $15 \%$ of adolescents report poor or fair SRH. ${ }^{33}$

As with our study, gender differences in SRH have been observed in previous studies in different settings. Male adolescents are more likely to report having good SRH than females. ${ }^{19} 202934$ Nevertheless, further studies are required to explore the factors associated with this gender difference in SRH. In this study, SRH did not significantly differ between early and late adolescence. However, age was a significant factor related to SRH in a study conducted in Brazil. ${ }^{17}$

In this study, $11.7 \%$ of respondents reported missing a meal in the last month due to a lack of food at home. In contrast, only $3.2 \%$ of students reported missing a meal according to the Global School-based Student Health Survey conducted in 2010. This discrepancy may suggest a lower socioeconomic status (SES) among our study sample compared with the average SES in Peru. ${ }^{28}$ Furthermore, the study revealed that missing a meal due to shortages of food was significantly associated with poor/fair SRH. However, we did not measure monthly household income or other SES indicators, which was one of the limitations of our study. Other studies have also observed that SRH is strongly associated with SES. ${ }^{15}{ }^{17}$ Additionally, lack of fruit consumption during the previous week was related to poor/fair SRH in model 1. Consistent with this finding, a similar association was observed by Meireles et al. ${ }^{17}$ In this study, family support was strongly associated with SRH, indicating that more family support reduces the risk of poor/ fair SRH. Lack of parental understanding was found to be positively associated with poor SRH among Pakistani adolescents. ${ }^{18}$ Among Brazilian adolescents, poor family support was also associated with poor SRH. ${ }^{17}$ Thus, family support appears to be very important for adequate physical, mental and psychological health throughout adolescence.

In this study, smoking status and alcohol consumption did not have a significant impact on SRH. However, several studies reveal that smoking ${ }^{12} \quad 15 \quad 19 \quad 33 \quad 35$ and alcohol abuse ${ }^{19}$ are risk factors for poor SRH. Moreover, poor SRH has been strongly associated with alcoholrelated and drug-related deaths. ${ }^{6}$ Physical activity, or a more active lifestyle, tends to be positively associated with SRH. ${ }^{12} 1415203036$ Our study observed that physical activity of at least $1 \mathrm{~h}$ each day for 3 or more days per week was associated with a reduced likelihood of poor/fair SRH, similar to what was found in Erginoz et $a .^{20}$ However, $>4 \mathrm{~h}$ of physical activity per week was an important factor in SRH, but only for boys in a study from Elinder et al. ${ }^{37} \mathrm{~A}$ linear trend has been shown between physical activity and SRH among both boys and girls, and health benefits can emerge from very low-level activities, especially among male adolescents. ${ }^{38}$ A Canadian study also revealed that physically inactive students are at an increased risk for poor SRH. ${ }^{19}$ Most importantly, graded and continuous associations with better SRH indicates that the effect of physical activity can be observed at a low level and increases with activity intensity. ${ }^{36}{ }^{39}$ Additionally, those who spent their leisure time watching TV were more likely to report poor/fair health in this study. Overall, the present results indicate that physical activity is a very important factor influencing health among adolescents. Finally, we observed that school absenteeism was statistically associated with poor/ fair SRH. However, the direction of this relationship is not fully clear.

No significant association was observed for perceived body weight and SRH in this study. This indicates that being overweight or underweight was not considered as a risk factor of poor health among Peruvian adolescents. However, previous studies have shown that perceived weight status has an influence on SRH, as well as a strong negative association with mental health. ${ }^{40-43}$ Additionally, life satisfaction is an important component of psychological health. As in our study, life satisfaction significantly predicted SRH. ${ }^{15} 17{ }^{33}$ However, a bidirectional relationship between SRH and life satisfaction could be present, each predisposing the other. ${ }^{44}$

\section{CONCLUSION}

This study observed that a sizeable proportion of our Peruvian adolescent sample perceived their health to be poor/fair. Being female, missing meals due to food shortages at home, an inactive lifestyle, poor family support and diminished life satisfaction significantly influenced SRH. Interventions that focus on providing food security, increasing physical activity for at least $1 \mathrm{~h}$ each day for 3 or more days per week, promoting outdoor activities during leisure time, strengthening family support and developing positive attitudes towards life may contribute to improved SRH among adolescents in Peru. On the basis of our findings, various public health measures could be emphasised in order to improve adolescent health status in Peru. First, healthpromoting school initiatives should be promoted and 
strengthened to increase physical activity among students at school and home. Second, an emphasis should be placed on improving supportive parental roles and strengthening adolescent-parent relationships. Involving parents in adolescent health programmes will most likely be very beneficial. Third, concerned organisations, including donor agencies, should address food security issues affecting children and adolescents. Fourth, gender differences should be considered while designing, implementing and monitoring adolescent health programmes. Overall, joint efforts between schools, families and communities are vital for healthy development during adolescence, given that adolescent health is affected by several social, behavioural and psychological factors.

Acknowledgements The authors express their special thanks to the study participants, school staff, field enumerators and all other partners in Peru who made this survey possible.

Contributors BS designed the study, analysed the data and drafted the manuscript. EWN contributed to the study's design, interpretation of results and revision of the manuscript. DK helped interpret the results and finalise the manuscript. YK designed the study and contributed to the finalisation of the manuscript. YMY performed the field survey and contributed to the finalisation of the manuscript. HYK prepared the data set and helped finalise the manuscript. All the authors read and approved the manuscript in its present form.

Funding The authors appreciate the support of the Korea International Cooperation Agency (KOICA) and the National Research Foundation of Korea (grant number NRF-2013S1A01055336) for financially supporting this study.

\section{Competing interests None declared.}

Ethics approval Ethical approval for this study was obtained from the Institutional Review Board of Wonju Campus, Yonsei University (1041849201410-BM-048-02) and the DIRESA Callao (local government of Peru).

Provenance and peer review Not commissioned; externally peer reviewed.

Data sharing statement No additional data are available.

Open Access This is an Open Access article distributed in accordance with the Creative Commons Attribution Non Commercial (CC BY-NC 4.0) license, which permits others to distribute, remix, adapt, build upon this work noncommercially, and license their derivative works on different terms, provided the original work is properly cited and the use is non-commercial. See: http:// creativecommons.org/licenses/by-nc/4.0/

\section{REFERENCES}

1. Bombak AE. Self-rated health and public health: a critical perspective. Front Public Health 2013;1:15-18.

2. Manor O, Matthews S, Power C. Self-rated health and limiting longstanding illness: inter-relationships with morbidity in early adulthood. Int J Epidemiol 2001;30:600-7.

3. Bath PA. Self-rated health as a risk factor for prescribed drug use and future health and social service use in older people. J Gerontol A Biol Sci Med Sci 1999;54:M565-70.

4. Abdulrahim S, El Asmar K. Is self-rated health a valid measure to use in social inequities and health research? Evidence from the PAPFAM women's data in six Arab countries. Int $J$ Equity Health 2012;11:53.

5. Heistaro S, Jousilahti P, Lahelma E, et al. Self-rated health and mortality: a long term prospective study in eastern Finland. $J$ Epidemiol Community Health 2001;55:227-32.

6. Larsson D, Hemmingsson T, Allebeck $P$, et al. Self-rated health and mortality among young men: what is the relation and how may it be explained? Scand J Public Health 2002;30:259-66.
7. Idler EL, Benyamini Y. Self-rated health and mortality: a review of twenty-seven community studies. J Health Soc Behav 1997;38:21-37.

8. Burström B, Fredlund P. Self related health: is it as good a predictor of subsequent mortality among adults in lower as well as in higher social classes? J Epidemiol Community Health 2001;55: 836-40.

9. Lima-Costa MF, Cesar CC, Chor D, et al. Self-rated health compared with objectively measured health status as a tool for mortality risk screening in older adults: 10-year follow-up of the Bambuí Cohort Study of Aging. Am J Epidemiol 2012;175:228-35.

10. Nam EW, Ikeda N, Green J, et al. Determinants of the self-rated health status of the elderly in Healthy City Wonju, Republic of Korea. Korean J Health Educ Promotion 2008;25:65-77.

11. Freidoony L, Chhabi R, Kim CS, et al. The components of self-perceived health in the Kailali District of Nepal: a cross-sectional survey. Int J Environ Res Public Health 2015;12:3215-31.

12. Vingilis ER, Wade TJ, Seeley JS. Predictors of adolescent self-rated health: analysis of the National Population Health Survey. Can J Public Health 2002;93:193-7.

13. Boardman JD. Self-rated health among US adolescents. J Adolesc Health 2006;38:401-8.

14. Breidablik HJ, Meland E, Lydersen S. Self-rated health in adolescence: a multifactorial composite. Scand J Public Health 2008;36:12-20.

15. Piko BF. Self-perceived health among adolescents: the role of gender and psychosocial factors. Eur J Pediatr 2007;166:701-8.

16. Breidablik HJ, Meland E, Lydersen S. Self-rated health during adolescence: stability and predictors of change (Young-HUNT study, Norway). Eur J Public Health 2009;19:73-8.

17. Meireles AL, Xavier CC, Proietti FA, et al. Influence of individual and socio-environmental factors on self-rated health in adolescents. Rev Bras Epidemiol 2015;18:538-51.

18. Afridi AA, Motwani K, Khawaja S, et al. Self-perceived health among school going adolescents in Pakistan: influence of individual, parental and life style factors? Glob J Health Sci 2013;5:71-8.

19. Tremblay S, Dahinten S, Kohen D. Factors related to adolescents' self-perceived health. Health Rep 2003;14(Suppl):7-16.

20. Erginoz E, Alikasifoglu M, Ercan O, et al. Perceived health status in a Turkish adolescent sample: risk and protective factors. Eur $J$ Pediatr 2004;16:485-94.

21. Viner RM, Ozer EM, Denny S, et al. Adolescence and the social determinants of health. Lancet 2012;379:1641-52.

22. Novak D, Suzuki E, Kawachi I. Are family, neighbourhood and school social capital associated with higher self-rated health among Croatian high school students? A population-based study. BMJ Open 2015;5:e007184.

23. Friberg P, Hagquist C, Osika W. Self-perceived psychosomatic health in Swedish children, adolescents and young adults: an internet-based survey over time. BMJ Open 2012;2:e000681.

24. Holstein BE, Hansen EH, Andersen A, et al. Self-rated health as predictor of medicine use in adolescence. Pharmacoepidemiol Drug Saf 2008;17:186-92.

25. UN data. Country profile, Peru. http://data.un.org/CountryProfile. aspx?crName=PERU (accessed on 2 Dec 2015).

26. Censos Nacionales 2007: XI de Población y VI de Vivienda. Perfil Socio demográfico del Perú. INEI-UNFPA-PNUD. Lima, 2008.

27. WHO. Peru: WHO statistical profile. http://www.who.int/gho/ countries/per.pdf?ua=1 (accessed on 1 Dec 2015).

28. Centre for Disease Control and Prevention, Global School-based Student Health Survey (GSHS). 2010. http://www.who.int/chp/gshs/ GSHS Report Peru 2010.pdf (accessed on 14 Sep 2015)

29. Zarini $\bar{G} G$, Vaccaro JA, Canossa Terris MA, et al. Lifestyle behaviors and self-rated health: the Living for Health Program. J Environ Public Health 2014;2014:315052.

30. Hosseini M, Maghami M, Kelishadi R, et al. First report on self-rated health in a nationally-representative sample of Iranian adolescents: the CASPIAN-III study. Int J Prev Med 2013;4:146-52.

31. Carmen MC, María MC, Yalile MB, et al. Iv estudio nacional: prevención y consumo de drogas en estudiantes de secundaria. Comisión Nacional para el Desarrollo y Vida Sin Drogas 2012: 18-118.

32. World Health Organization. Global School-based Student Health Survey (GSHS), questionnaire modules. 2013. http://www.who.int/ chp/gshs/GSHS_Core_Modules_2013_English.pdf (accessed on 14 Sep 2015).

33. Foti K, Eaton D. Associations of selected health risk behaviors with self-rated health status among US high school students. Public Health Rep 2010;125:771-81.

34. Jerdén L, Burell G, Stenlund $H$, et al. Gender differences and predictors of self-rated health development among Swedish adolescents. J Adolesc Health 2011;48:143-50. 
35. Wang MP, Ho SY, Lo WS, et al. Smoking is associated with poor self-rated health among adolescents in Hong Kong. Nicotine Tob Res 2012;14:682-7.

36. Dyremyhr AE, Diaz E, Meland E. How adolescent subjective health and satisfaction with weight and body shape are related to participation in sports. J Environ Public Health 2014;2014:851932.

37. Elinder LS, Sundblom E, Rosendahl KI. Low physical activity is a predictor of thinness and low self-rated health: gender differences in a Swedish cohort. J Adolesc Health 2011;48:481-6.

38. Galán I, Boix R, Medrano MJ, et al. Physical activity and self-reported health status among adolescents: a cross-sectional population-based study. BMJ Open 2013;3:e002644.

39. Galán I, Meseguer CM, Herruzo R, et al. Self-rated health according to amount, intensity and duration of leisure time physical activity. Prev Med 2010;51:378-83.
40. Meland E, Haugland S, Breidablik HJ. Body image and perceived health in adolescence. Health Educ Res 2007;22:342-50.

41. Herman KM, Hopman WM, Rosenberg MW. Self-rated health and life satisfaction among Canadian adults: associations of perceived weight status versus BMI. Qual Life Res 2013;22: 2693-705.

42. Ali MM, Fang H, Rizzo JA. Body weight, self-perception and mental health outcomes among adolescents. J Ment Health Policy Econ 2010;13:53-63.

43. Ozmen D, Ozmen E, Ergin D, et al. The association of self-esteem, depression and body satisfaction with obesity among Turkish adolescents. BMC Public Health 2007;7:80.

44. Zullig KJ, Valois RF, Huebner ES, et al. Adolescent health-related quality of life and perceived satisfaction with life. Qual Life Res 2005;14:1573-84. 